\title{
Prevalence of rheumatoid arthritis and rheumatoid factor in women: evidence for a secular decline
}

\author{
Tim D Spector, Deborah J Hart, Richard J Powell
}

\begin{abstract}
Objective-To determine the current prevalence of rheumatoid arthritis (RA) and rheumatoid factor positivity in the United Kingdom middle aged female population and to compare this with previous estimates to assess whether the disease is becoming less prevalent.

Methods-A cross sectional prevalence study was undertaken. All women aged 45-64 from the age and sex register of a large 11000 general practitioner group practice in Chingford, East London were contacted and responders examined clinically and radiographically for the presence of RA by a single observer. Blood was also taken for rheumatoid factor testing (sheep cell agglutination test (SCAT), latex, and IgG). The prevalence in nonattenders was assessed from general practitioner and local hospital records. A diagnosis of definite or classical RA according to 1958 American Rheumatism Association criteria was used, and seropositivity was defined by a SCAT rheumatoid factor of $1 / 32$ or more.
\end{abstract}

Results-From the 1003 women examined (response rate of $78.8 \%$ ), 12 women had definite RA $(1 \cdot 2 \%, 95 \%$ confidence interval 0.6 to $1 \cdot 8)$. Of these, $7 / 12 \mathrm{had}$ definite erosive changes on radiography and $3 / 12$ had a positive SCAT $(>1 / 32)$. Three cases of RA were also found in the 284 non-responders (prevalence $1 \cdot 1 \%$ ) by case-finding techniques. The rate of SCAT positivity in the whole study group was $0.5 \%$. The rates of $R A$ and SCAT positivity currently found in this group were less than those obtained in previous surveys. In the only previous large scale United Kingdom survey, performed in the north of England between 1958 and 1960 , 406 women aged 45-64 were examined and 10 cases of definite RA were found, a prevalence of $2 \cdot 5 \%$. In the patients with RA $68 \%$ had erosions and $63 \%$ positive SCAT. The population SCAT positive rate in this and other surveys sampled between 1954 and 1961 was in the range of $4-5 \%$, since when there has been a progressive decline according to a number of other studies.

Conclusions-The prevalence of RA and rheumatoid factor in middle aged women is lower than previously believed and supports a variety of other data which indicate that RA is declining in incidence and severity.

(Ann Rheum Dis 1993; 52: 254-257)

Rheumatoid arthritis (RA) is a chronic inflammatory disorder of unknown cause with a characteristic pattern of joint involvement. There is no current information on the prevalence of RA or the frequency of positive serum rheumatoid factors in the United Kingdom. The last survey was carried out 30 years ago and the results are still used to estimate disease prevalence for a variety of purposes, including clinical trials, epidemiological studies, and health planning. ${ }^{1}$ Serum rheumatoid factor is an autoantibody which reacts against the Fc portion of IgG, which is not only commonly associated with the disease but may appear several years before the disease becomes clinically apparent. Its appearance at high titre in serum is regarded as a risk factor for the later development of RA. ${ }^{2}$ There is currently speculation as to whether the prevalence of RA has declined over the past three decades. We therefore undertook a population survey using standard diagnostic criteria in women aged 45-64 drawn from a large general practitioner group practice in Chingford, East London (table 1). The aims were to obtain estimates of the prevalence of RA and serum rheumatoid factors in the middle aged female population and compare these with previous studies.

\section{Methods}

All the women aged between 45 and 64 years recorded on the age-sex register of the 11000 person group practice $(n=1353)$ were sent an invitation to attend the local hospital for screening. All women were examined by a

\section{Table 1 Characteristics of the Chingford study group}

\begin{tabular}{|c|c|}
\hline $\begin{array}{l}\text { Number of women aged } 45-64 \\
\text { Number of women examined } \\
\text { Mean age (SD) } \\
\text { Mean weight (kg) (SD) } \\
\text { Number of 'definite' cases } \\
\quad(1958 \text { ARA } \text { criteria })^{-}\end{array}$ & $\begin{array}{l}1353 \\
1003 \\
54 \cdot 2(6.03) \\
66 \cdot 9(11 \cdot 84) \\
12\end{array}$ \\
\hline $\begin{aligned} & \text { No }(\%) \text { SCAT }^{\star} \text { positive }(<1 / 8) \dagger \\
&(>1 / 32)\end{aligned}$ & $\begin{array}{r}70(7 \cdot 4) \\
5(0 \cdot 5)\end{array}$ \\
\hline $\begin{array}{l}\text { No(\%) latex fixation test positive } \\
\text { No(\%) IgG rheumatoid factor positive }\end{array}$ & $\begin{array}{l}114(12 \cdot 0) \\
122(12 \cdot 8)\end{array}$ \\
\hline
\end{tabular}

^ARA=American Rheumatism Association; SCAT $=$ sheep cell agglutination test.

tBased on 950 cases. 
single observer between 1989 and 1990 for clinical signs of RA and a standard anteroposterior radiograph of the hands was taken. Radiographs were read by two clinicians unaware of the clinical findings but aware that the subjects were suspected of having RA. The presence or absence of erosions was judged using standard photographs provided in Lawrence's reference textbook. ${ }^{3}$ Rheumatic disease symptoms used in the diagnostic criteria, including the presence of morning stiffness, were also recorded. Any woman with symptoms or signs suggestive of RA had blood taken for erythrocyte sedimentation rate determination and additional $x$ ray examination if indicated. The 1958 American Rheumatism Association criteria were used to be consistent with previous surveys. ${ }^{4}$ To reduce misclassification we used only the category 'definite' RA, which requires at least five criteria to be present. To identify any possible cases that were not examined we searched the general practitioner records of non-responders for evidence of recorded RA. The rheumatological databases of the local hospitals were also searched for any patients registered with the group practice.

Blood was taken and serum stored at $-20^{\circ} \mathrm{C}$ before testing for rheumatoid factors. The following assays were included:

Sheep cell agglutination test (SCAT) used sheep cells sensitised with rabbit IgG. ${ }^{5}$ The agglutination reaction was graded between $1: 8$ and 1:2048 dilution and the international reference preparation of rheumatoid arthritis serum, supplied by the WHO, was used as the external quality control in each SCAT run.

Latex agglutination test (Rapi-Tex, Behring) The reagent is latex passively coated with human polyclonal IgG and the agglutination with serum, diluted 1 in 10 , performed on a slide and read visually, scoring 0 to +++ .

IgG class specific rheumatoid factor test This has been adapted to an enzyme linked immunosorbent assay (ELISA) ${ }^{6}$ but remains a solid phase assay using affinity purified human polyclonal IgG Fc as antigen, to which rheumatoid factors may bind. IgG rheumatoid factors were specifically detected using an alkaline phosphatase conjugated sheep $\left(\mathrm{Fab}^{\prime}\right)_{2}$ IgG antihuman IgG Fd. Raised levels were reported as $2 \cdot 5$ standard deviations above the mean of the normal range.

\section{Results}

One thousand and three women attended for an examination; 66 had left the area, eight were too ill, and six had died, giving a response rate of $78.8 \%$. Of the women examined 12 were found to have definite RA by the 1958 criteria

Table 2 Relation of rheumatoid factors in 941 women without rheumatoid arthritis

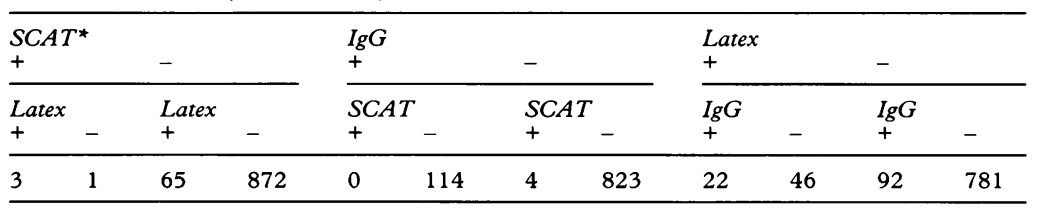

* $\mathrm{SCAT}=$ sheep cell agglutination test. (and 11 by the 1987 criteria). All patients had current clinical evidence of disease; we did not find any asymptomatic subjects with inactive disease and deformity. Three cases of RA were also found amongst the 284 non-responders $(1 \cdot 1 \%)$ by case-finding techniques. The prevalence of RA in those examined was $1.2 \%$ ( $95 \%$ confidence interval $(\mathrm{CI}) 0.6$ to 1.8 ) in women aged 45-64.

Rheumatoid factors were analysable in 950 serum samples. Low titre SCAT tests $(<1 / 8)$ were positive in $70(7.4 \%)$ of women but in only five $(0.5 \%)$ at the clinically significant titre of $\geqslant 1 / 32$. Positivity to the latex fixation test was found in $114(12.0 \%)$ and to the IgG rheumatoid factor test in $122(12 \cdot 8 \%)$. Of the 12 women with RA according to the 1958 criteria, seven $(58 \%)$ had some evidence of definite erosive changes on radiography. Three women $(25 \%)$ were positive by SCAT test $(\geqslant 1 / 32), 8 / 12(67 \%)$ had a positive latex rheumatoid factor, and $6 / 12(50 \%)$ were positive by IgG rheumatoid factor. There was agreement between latex and SCAT in 10/12 cases, between IgG and SCAT in 9/12, and between IgG and latex in $11 / 12$ cases. Only three women were seronegative for all three tests. Three of the 12 women had definite RA which had not been previously diagnosed by their general practitioner or appropriate specialist. Table 2 shows the relation between the rheumatoid factors in a group of women without RA. There was little agreement between the different tests in this group.

\section{Discussion}

To date this is the largest prevalence survey for RA performed in middle aged women in the United Kingdom. The $1 \cdot 2 \%$ prevalence of RA is less than that quoted in most previous studies of women in developed countries, who have a two- to threefold greater incidence than men. ${ }^{8}$ The level of seropositivity for rheumatoid factor was also low. The first question to be asked is whether the group surveyed were representative of women in the United Kingdom. Between 1986 and 1988, as part of a study of the effect of hormone replacement on RA, we estimated the prevalence of RA in a group of 3251 women aged 35-64 registered with 14 general practitioners based in inner and outer London. ${ }^{9}$ Using a screening questionnaire and staged clinical examination of the positive respondents, we found a rate of RA of $1 \cdot 2 \%$ (41 cases) using the 1987 criteria. Although performed on a larger group, this previous survey was more prone to misclassification because in $40 \%$ of cases a diagnosis was made from medical records and history without a standardised examination. In addition, it is possible that a few cases might not have responded accurately to the screening questionnaire. Despite these problems the two London based surveys do give equivalent results, suggesting that the Chingford sample was representative of women in the London area. In addition, the mean heights, weights, and body mass index were found to be similar 
Table 3 Population studies of SCAT ${ }^{\star}$ rheumatoid factor positivity reported as $1 / 20$ or $1 / 32$ titre

\begin{tabular}{llllrll}
\hline Year of survey & Site/country & Age range & Sex & $n$ & $\begin{array}{l}\text { SCAT } \\
\text { positivity (\%)* }\end{array}$ & Reference No \\
\hline 1955 & N England & $35+$ & $\mathrm{M}+\mathrm{F}$ & 1670 & $4 \cdot 6$ & 10 \\
$1954-61$ & N Europe & $55-64$ & $\mathrm{M}+\mathrm{F}$ & 1795 & 3.9 & 11 \\
1958 & N England & $45-64$ & $\mathrm{~F}$ & 406 & $6 \cdot 0$ & 1 \\
1963 & Virginia, USA & $30-89$ & $\mathrm{M}+\mathrm{F}$ & 2633 & $3 \cdot 4$ & 12 \\
1965 & Sudbury, USA & $45-74$ & $\mathrm{M}+\mathrm{F}$ & 1105 & $2 \cdot 5$ & 13 \\
1968 & Iceland & $30-64$ & $\mathrm{~F}$ & 2321 & $2 \cdot 0$ & Valkenburg \\
$1975-8$ & Netherlands & $20+$ & $\mathrm{M}+\mathrm{F}$ & 6000 & $4 \cdot 4$ & (personal communication) \\
$1978-80$ & Finland & $30+$ & $\mathrm{M}+\mathrm{F}$ & 7217 & 1.9 & Valdimarsson \\
$1974-83$ & Iceland & $39-76$ & $\mathrm{M}+\mathrm{F}$ & 13858 & $1 \cdot 0$ & (personal communication) \\
& & & & & \\
1984 & N Norway & $20-49$ & $\mathrm{M}+\mathrm{F}$ & 8807 & 1.5 & Present study \\
1990 & S England & $45-64$ & $\mathrm{~F}$ & 950 & 0.5 &
\end{tabular}

$\star$ SCAT $=$ sheep cell agglutination test.

to the national average. Although social class has not been shown in the United Kingdom to be associated with the incidence of RA, our group contained women from all social strata. According to the Acorn postcode classification system (CACI Ltd, London) $42 \%$ were of middle class white collar worker status (C1), $32 \% \mathrm{~A} / \mathrm{B}, 17 \% \mathrm{C} 2$, and $8 \% \mathrm{D} / \mathrm{E}$.

There are few previous data with which to compare these age and sex specific rates. World wide the most comparable single study in terms of methodology with adequate numbers of women aged $45-64$ is the study of Lawrence et al based in Leigh and Wensleydale performed between 1955 and $1960 .{ }^{1}$ In that study 406 women were examined between the ages of 45 and 64 and 10 cases of definite RA were found, a prevalence of $2 \cdot 5 \%$ (95\% CI $1 \cdot 2$ to $4 \cdot 9$ ). Although this was twice the prevalence found in the present survey, the difference did not reach conventional statistical significance ( $\chi^{2}$ test, $\mathrm{p}=0 \cdot 1$ ), and might have been due to chance. Although it is difficult to ascertain from the published report the exact methods of diagnosis used in the earlier survey, this also used clinical and radiological examination and, in theory, the same diagnostic criteria as the present study.

High titres of rheumatoid factor are considered to be a risk factor for the development of RA indicating an early preclinical stage of the disease ${ }^{2}$ and also a worse prognosis. The levels of SCAT rheumatoid factor in our group $(0.5 \%)$ were markedly lower than those reported by Lawrence in the Leigh and Wensleydale surveys, who found positive levels in $6.0 \%$ of women in the same age range. ${ }^{1}$ Table 3 summarises a number of published and unpublished large scale surveys of SCAT positivity in the population since $1954 .^{1{ }^{10-16}}$ The only centre to repeat the SCAT test on a group at a later date using the same method and technician was in Reykjavik, where the SCAT rate fell from $1 \cdot 23 \%$ in 4297 men and women aged 34-61 surveyed between 1967 and 1969 to $1.0 \%$ in 13858 subjects surveyed between 1974 and 1983, a fall of $23 \%$ in 10 years (Valdimarsson, personal communication). Overall the surveys show a diminishing prevalence of SCAT positivity in recent years.

The SCAT or Rose-Waaler test is the only rheumatoid factor that can be reliably used for comparisons between centres and has not been found to vary consistently between the sexes.
The SCAT test has remained much the same since it became widely used in the $1950 \mathrm{~s},{ }^{56}$ and a WHO standard is now used by most centres. All studies quoted used a $1 / 20$ or $1 / 32$ dilution as a positive result. It is therefore unlikely that major methodological differences could account for the 10 -fold difference in seropositivity found in our study with that reported in a number of centres 30 years before. Why SCAT positivity appears to have been far more common in the past is far from clear. Levels were originally reported to be higher in urban rather than rural areas, ${ }^{1}$ though present populations are likely to be more exposed to urban environments than in the past. The effect of chronic infections, particularly of the chest, has been linked to high rheumatoid factor titres. ${ }^{3}$ Reduced levels of exposure to agents such as brucellosis, tuberculosis, or streptococci in recent years may be responsible. The latex and $\operatorname{IgM}$ rheumatoid factor tests were shown to be highly sensitive but to be of little use in population studies owing to their low specificity. It is not possible to compare these results with previous surveys as the two tests are not standardised across centres and raised levels are reported at a cut off point based on the individual laboratory normal range.

Taken in isolation the results of the present prevalence survey are not conclusive, and as with any prevalence study the result might have arisen either because of a reduced incidence of the disease or, alternatively, a reduction in disease duration (possibly affected by successful treatment). Evidence for the former is supported by data from a number of incidence studies over different time periods. Linos et al showed a $60 \%$ decline in the incidence of RA in women (but not men) in Rochester, Minnesota between 1960 and $1974 .{ }^{17}$ Hochberg observed a $20 \%$ decline in women (but not men) using data from the second and third national studies of morbidity in general practice in England and Wales between 1970 and $1982 .{ }^{18}$ Silman reported a decline of $50 \%$ in both men and women between 1976 and 1987 according to monthly returns from selected practices to the Royal College of General Practitioners (RCGP) Research Unit. ${ }^{19}$ A recent survey of the incidence of RA in women in Seattle found rates $45 \%$ lower than the average reported from the Rochester epidemiology project between 1960 and 
$1974 .^{20}$ Finally, Hannaford et al recently resurveyed a cohort of women in the RCGP oral contraceptive pill study and found a $46 \%$ reduction in incidence between 1968 and 1987 in non-pill users. ${ }^{21}$

It is possible that a change has occurred in the pattern of RA. Several studies have reported that the disease currently seen appears to be milder than in the past. ${ }^{22-24}$ Our survey showed, in the small numbers of patients with RA detected, low levels of SCAT seropositivity and lower rates of definite erosions than in the Leigh and Wensleydale surveys. Although the comparison of frequency of erosions is difficult to standardise accurately without directly comparing the films, these results support the suggestion that the disease is less severe in presentation. The increasing use of oral contraceptives in women over the past three decades has been suggested as a cause of the decline in RA. ${ }^{17}$ Although overall most studies support a protective or modest disease modifying effect, ${ }^{25}$ however, this would not explain the apparently similar decline in men. Each of the studies showing changes in the incidence of RA can easily be individually criticised on methodological grounds. It is unlikely, however, that there is a systematic bias common to them all. It is also unlikely that $\mathrm{RA}$ is being currently underdiagnosed around the world. Therefore the weight of available evidence firmly supports our findings of a reduced prevalence of both $R A$ and serum rheumatoid factor in middle aged women compared with previous estimates, suggesting that the pattern and incidence of the disease may be changing. Old estimates of the prevalence of RA should therefore not be used for current research and resource allocation purposes.

This study was supported in part by a grant from the joint research board of St Bartholomew's Hospital. We would like to thank the patients and staff of the Handsworth Avenue group practice, Chingford Hospital and Dr David Doyle and the practice, Chingford Hospital and Dr David Doyle and the department of rheumatology at Whipps Cross and Wanstead
Hospital for help and support. Thanks must also go to the staff of the department of immunology, Queen's Medical Centre for of the department of immunology, Queen's Medical Centre for the rheumatoid factor testing. We are grateful for the advice of Dr Malcolm Law in preparing this manuscript and to Professor
Allander of Stockholm, Professor Valkenburg of Rotterdam Allander of Stockholm, Professor Valkenburg of Rotterdam,
and Professor Valdimarsson of Reykjavik for additional information about their studies.

1 Lawrence J S. Prevalence of rheumatoid arthritis. Ann Rheum Dis 1961; 20: 11-17.
2 MacGregor A J, Silman A J. Rheumatoid factors as predictors of rheumatoid arthritis. $\mathcal{F}$ Rheumatol 1991; 18: 1280-1.

3 Lawrence J S. Rheumatism in populations. London: Heinemann, 1977.

4 Ropes M S, Bennett G A, Cobb S, et al. 1958 revision of diagnostic criteria for rheumatoid arthritis. Bull Rheum Dis 1958; 9: 175-6.

5 Waaler E. On the occurrence of a factor in human serum activating the specific agglutination of sheep cell corpuscles. Acta Pathol Microbiol Scand 1940; 17: 172 .

6 Powell R J, Leyland A M, Pound J D, Bossingham D H. An improved assay for IgG rheumatoid factor: its value in the diagnosis of rheumatoid arthritis. $\mathcal{F}$ Rheumatol 1985; 12: 427-31

7 Hopkinson N D, Powell R J, Doherty M. Auto-antibodies, immunoglobulins and $\mathrm{Gm}$ allotypes in nodal generalised osteoarthritis. Br f Rheumatol 1992; 31: 605-8.

8 Spector T D. Rheumatoid arthritis. The epidemiology of the rheumatic diseases. Rheum Dis Clin North Am 1990; 16: 513-37.

9 Spector T D, Brennan P, Harris P, Studd J W W, Silman A J. Does estrogen replacement therapy protect against rheumatoid arthritis? F Rheumatol 1991; 18: 1473-6.

10 Ball J, Lawrence J S. Epidemiology of the sheep cell agglutination test. Ann Rheum Dis 1961; 20: 235-7.

11 De Graaf R, Laine V, Lawrence J S. Comparison of surveys in various Northern European countries. In: Kellgren J H, Jeffrey M R, Ball J, eds. The epidemiology of chronic rheumatism. Oxford: Blackwell Scientific, 1963: 74-81.

12 Waller M, Toone E C, Vaughan E. Study of rheumatoid factor in a normal population. Arthritis Rheum 1964; 7: 513-20.

13 Cathcart E S, O'Sullivan J B. A longitudinal study of rheumatoid factors in a New England town. Ann $N Y$ Acad Sci 1969; 168: 41-50.

14 Allander E, Bjornsson O, Kolbeinsson A, Olafson $O$ Sigfusson N, Thorsteinsson J. Rheumatoid factor in Iceland: a population study. Int $\mathcal{F}$ Epidemiol 1972; 1: 211-23.

15 Aho $K$, Heliovaara $M$, Maatela J, Tuoni T, Palosuo T Rheumatoid factors antedating clinical rheumatoid arthritis. $\mathcal{F}$ Rheumatol 1991; 18: 1282-4

16 Gran J T, Johannessen A, Husby G. A study of IgM rheumatoid factors in a middle aged population of Northern Norway. Clin Rheumatol 1984; 3: 163-8.

17 Linos A, Worthington J W, O'Fallon M, Kurland L T. The epidemiology of rheumatoid arthritis in Rochester, Minnesota: a study of incidence, prevalence and mortality. $A m$ ₹ Epidemiol 1980; 111: 87-98.

18 Hochberg M C. Changes in the incidence and prevalence of rheumatoid arthritis in England and Wales 1970-82. of rheumatoid arthritis in England

19 Silman A J. Has the incidence of rheumatoid arthritis declined in the United Kingdom? Br $\mathcal{f}$ Rheumatol 1988; 27: 77-9.

20 Dugowson C E, Bley L, Koepsell T D, Nelson J L, Daling J R. Rheumatoid arthritis in women: incidence rates in a group Health Cooperative, Seattle, Washington, 1987-9. Arthritis Rheum 1991; 34: 1502-7.

21 Hannaford P C, Kay C R, Hirsch S. Oral contraceptives and rheumatoid arthritis: new data from the Royal College of General Practitioners' oral contraception study. Ann Rheum Dis 1990; 49: 744-6.

22 Silman A J, Davies P, Currey H L F, Evans S J W. Is rheumatoid arthritis becoming less severe? $\mathcal{f}$ Chronic Dis 1983; 36: 891-7.

23 Anderson J J, Felson D T, Meenan R F. Secular changes in published clinical trials of second line agents in rheumatoid arthritis (RA) clinical trials. Arthritis Rheum 1991; 34: 1304-9.

24 Laurent R, Robinson R G, Beller E M, Watson Buchanan W. Incidence and severity of rheumatoid arthritis-the view from Australasia. Br f Rheumatol 1989; 28: 360-1.

25 Spector T D, Hochberg M C. A meta-analysis of the association between the oral contraceptive pill and the development of rheumatoid arthritis. Clin Epidemiol 1990 43: $1221-30$. 